Provided for non-commercial research and education use. Not for reproduction, distribution or commercial use.

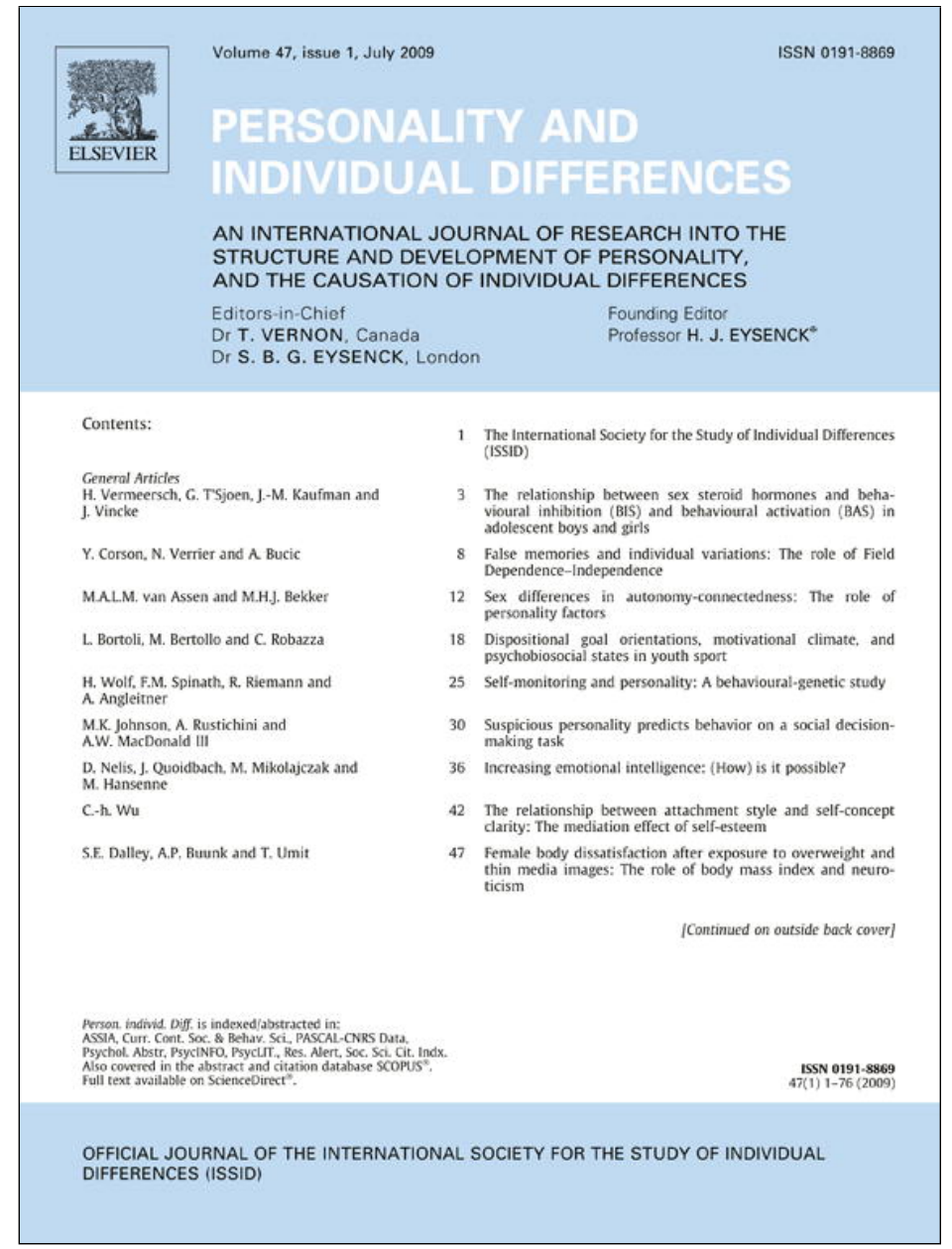

This article appeared in a journal published by Elsevier. The attached copy is furnished to the author for internal non-commercial research and education use, including for instruction at the authors institution and sharing with colleagues.

Other uses, including reproduction and distribution, or selling or licensing copies, or posting to personal, institutional or third party websites are prohibited.

In most cases authors are permitted to post their version of the article (e.g. in Word or Tex form) to their personal website or institutional repository. Authors requiring further information regarding Elsevier's archiving and manuscript policies are encouraged to visit:

http://www.elsevier.com/copyright 
Short Communication

\title{
Mental toughness in sport: Achievement level, gender, age, experience, and sport type differences
}

\author{
Adam R. Nicholls ${ }^{\mathrm{a}, *}$, Remco C.J. Polman ${ }^{\mathrm{b}}$, Andrew R. Levy ${ }^{\mathrm{c}}$, Susan H. Backhouse ${ }^{\mathrm{d}}$ \\ a University of Hull, Department of Psychology, Cottingham Road, Hull HU6 7RX, United Kingdom \\ ${ }^{\mathrm{b}}$ Centre for Applied Sport and Exercise Sciences, University of Central Lancashire, United Kingdom \\ ${ }^{\mathrm{c}}$ Centre of Sport and Exercise Science, University of Leeds, United Kingdom \\ ${ }^{\mathrm{d}}$ Carnegie Research Institute, Leeds Metropolitan University, United Kingdom
}

\section{A R T I C L E I N F O}

\section{Article history:}

Received 4 November 2008

Received in revised form 26 January 2009

Accepted 3 February 2009

Available online 14 March 2009

\section{Keywords:}

Mental toughness

Gender

Achievement level

Skill

Chronological age

\begin{abstract}
A B S T R A C T
It was hypothesized that there would be significant differences in mental toughness among athletes of different: (a) achievement level, (b) gender, (c) age, (d) sporting experience, and (e) sport type (team vs. individual and contact vs. non-contact sports). Participants were 677 athletes and consisted of sports performers competing at international $(n=60)$, national $(n=99)$, county $(n=198)$, club/university ( $n=289$ ), and beginner ( $n=31$ ) levels. Results revealed a significant relationship between mental toughness and gender, age, and sporting experience. However, achievement level and the type of sport an athlete participated in was not significantly associated with mental toughness.
\end{abstract}

(c) 2009 Elsevier Ltd. All rights reserved.

\section{Introduction}

Clough, Earle, and Sewell (2002) suggested a mentally tough athlete has "a high sense of self-belief and an unshakable faith that they control their own destiny, these individuals can remain relatively unaffected by competition and adversity" (p. 38). Clough and colleagues proposed that mental toughness (MT) consists of a number of components labelled the 4Cs: (a) control (emotional and life), a tendency to feel and act as if one is influential, (b) commitment, a tendency to involve oneself in rather than experience alienation from an encounter, (c) challenge, belief that life is changeable and to view this as an opportunity rather than a threat, and (d) confidence (interpersonal and in abilities), a high sense of self-belief and unshakable faith concerning one's ability to achieve success. To date, researchers have tended to focus on defining and describing MT without exploring the relationship between MT and variables such as achievement level, gender, age, sporting experience, or sport type.

Despite scholars citing MT as a crucial construct in determining athletic success (e.g., Loehr, 1986), research concerning achievement level and MT is meager. A study by Golby and Sheard (2004) examined MT among a sample of 115 male rugby league

\footnotetext{
* Corresponding author. Tel.: +44 1132620931.

E-mail address: A.Nicholls@hull.ac.uk (A.R. Nicholls).
}

players of international, Super League, and Division 1 standard. Small differences in negative energy and attention control were found. However, comparing athletes with greater variability in achievement level may reveal larger differences. In a different study, Shin and Lee (1994) explored MT between elite and nonelite Korean female athletes. The elite athletes were more mentally tough than their non-elite counterparts, although no differences were found for arousal and attention control. Although the study by Shin and Lee (1994) featured female athletes, to our knowledge, there are no studies forthcoming that have systematically explored gender differences in MT.

Evidence from developmental sport psychology research has found young and older adults differ in their self-perceptions, social influences, emotional responses, motivations, and self-regulation with regard to sport and exercise participation (Weiss, 2004). Therefore, the role of developmental factors, such as age, could potentially influence MT. Alternatively, it could be argued that sport experience is a more subtle measure than age. Connaughton, Wadey, Hanton, and Jones (2008) reported that competitive experience was a crucial factor in the development of MT among athletes.

Although recent research has provided information regarding the concept of MT, little is known about potential variables that may be related to MT. Based on the current MT literature, we predicted that higher levels of achievement would be associated with higher levels of MT. Following Connaughton et al. (2008) it was predicted that older and more experienced athletes would exhibit 
higher levels of MT. We also hypothesized that males and team sport athletes would report higher MT scores than females or individual sport athletes. This is because confidence is a key component of MT (e.g., Clough et al., 2002), and males have been reported as being more confident than females and team sport athletes more confident than individual sport athletes (Vealey, 1988); Also, Bull, Shambrook, James, and Brooks (2005) have suggested that MT might be specific to certain sports. This could possibly result in differences between team and individual athletes as well as those competing in contact and non-contact sports, with the suggestion that those athletes participating in contact sport being more mentally tough.

\section{Method}

\subsection{Participants}

Participants were 677 athletes (male $n=454$; female $n=223$ ) aged between 15 and 58 years $(M$ age $=22.66, \mathrm{SD}=7.20)$, with experience in their sport ranging from 0.3 to 44 years ( $M$ experience $=11.65$ years, $S D=7.43)$. The athletes competed at international $(n=60)$, national $(n=99)$, county $(n=198)$, club/university $(n=289)$, and beginner $(n=31)$ levels. Additionally, the sample consisted of team sport $(n=482)$ and individual sport athletes $(n=195)$, who participated in contact $(n=311)$ and non-contact $(n=366)$ sports.

\subsection{Questionnaire}

Participants completed demographic information about their level of achievement, gender, age, experience, and type of sport and then completed the 48-item Mental Toughness Questionnaire (MTQ48; Clough et al., 2002). The MTQ48 assesses total MT and six subcomponents: challenge, commitment, interpersonal confidence, confidence in own abilities, emotional control, and life control. The items on the MTQ48 were rated on a 5-point Likert-type scale anchored at $1=$ Strongly disagree and $5=$ Strongly agree. The MTQ48 in this study had an overall Cronbach's Alpha value of 0.87 with all individual scales scoring between 0.58 and 0.71 . A recent exploratory and confirmatory factor analysis by Horsburgh, Schermer, Veselka, and Vernon (2009) suggests that the MTQ48 has acceptable psychometric properties. Previous research has shown its predictive and construct validity (e.g., Nicholls, Polman, Levy, \& Backhouse, 2008).

\subsection{Procedure}

An information letter and consent form was distributed to athletes. Assent and consent forms for parents/guardians were also distributed for participants who were under 16 years of age.

\subsection{Data analyses}

Data were first screened for outliers and normality. Internal consistency of the MTQ48 and descriptive statistics were calculated on all study variables prior to statistical analysis. The females in the present study were significantly younger $(M=21.46, \mathrm{SD}=$ 4.87 vs. $\left.M=23.26, S D=8.10: t_{675}=3.05 ; p<.01\right)$ and less experienced $\left(M=10.09, \mathrm{SD}=5.02\right.$ vs. $M=12.43, \mathrm{SD}=8.26: t_{675}=3.88$; $p<.01$ ) than the males. We therefore conducted multivariate analyses of co-variance (MANCOVA) to establish whether there were gender differences in the MT subscales with age and years of experience as co-variants. Two multivariate analysis of variance (MANOVA) were conducted to test whether team/individual, contact/non-contact or competitive level were associated with differences in the MT subscales. Follow-up univariate analysis of variance was executed in the instance of a significant main effect. Separate univariate analysis of variance (ANOVA) was conducted for total MT (total MT is highly correlated with the subscales and cannot be included in the MANCOVA or MANOVA). Finally, we conducted a linear regression analysis to ascertain the relationship between years of experience, age (predictor variables), and MT (either total MT or the six subscales of the MTQ48 as dependent variables).

\section{Results}

The descriptive statistics for gender and skill level in relation to control, commitment, challenge, confidence, and total MT are presented in Table 1. The MANCOVA for gender was significant (Wilks' $\lambda=0.97 ; p<0.01$ ). The follow-up univariate analysis of variance showed that the males scored significantly higher $(p<0.05)$ on challenge, control emotions, control life, and confidence ability, but not commitment or interpersonal confidence. However, the 2 (team/individual) by 2 (contact/non-contact) MANOVA did not show any main effects for type of sport (Wilks' $\lambda=0.99 ; p=0.63$ ), contact (Wilks' $\lambda=1.00 ; p=0.98$ ) or interaction effect (Wilks' $\lambda=0.99 ; p=0.70$ ).

Due to the differences between the male and female athletes in MT, a 5 (level of achievement) by 2 (gender) MANOVA was conducted. There was a significant gender main effect (Wilks' $\lambda=0.98 ; p=0.02$ ) but a non-significant achievement level main effect (Wilks' $\lambda=0.96 ; p=0.25$ ) and interaction effect (Wilks' $\lambda=$ $0.95 ; p=0.06)$.

The ANCOVA for total MT showed a significant effect for gender $(F(1,672)=11.99 ; p<.010)$ with the males scoring higher than the females. The ANOVAs for sport type and achievement level were not significant $(p>.05)$. As there were significant differences in gender and MT we controlled for gender in the regression analysis. Gender was entered at Step 1 and age or years of experience at Step 2 . Both age and years of experience significantly (all $p<.01$ ) predicted total MT $\left(\Delta R^{2}=.03, \beta=.18 ; \Delta R^{2}=.03, \beta=.17\right.$ for age and years of experience, respectively), challenge $\left(\Delta R^{2}=.02, \beta=.14\right.$; $\left.\Delta R^{2}=.03, \beta=.18\right)$, commitment $\left(\Delta R^{2}=.04, \beta=.21 ; \Delta R^{2}=.03, \beta=\right.$ $.17)$, and life control $\left(\Delta R^{2}=.02, \beta=.16 ; \Delta R^{2}=.03, \beta=.18\right)$.

\section{Discussion}

The results of the present study did not support the often held assertion that athletes of higher achievement levels are more mentally tough. This finding, along with Golby and Sheard's (2004) results, suggest that differences between levels of athletic achievement are minimal or subtle and that other factors like physical attributes, technical skill, or different psychological factors predict achievement level more accurately. Although caution is warranted given that the present study recruited a small number of elite athletes compared to other skill levels. However, results would suggest that conceptualizations of MT based on elite athletes and coaches only (e.g., Connaughton et al., 2008), may have significant limitations.

Males scored significantly higher than females on total MT and the four subscales challenge, control emotions, control life and confidence ability the latter partially supporting previous research on confidence. These differences could be due to variations in the underlying expression of the attributes related to MT in males and females or, alternatively, to different socialisation processes.

Increasing age and years of experience was shown to predict higher scores in total MT and the challenge, commitment, and life control subscales. The amount of variance accounted for by age and years of experience for changes in MT or its subcomponents was 
Table 1

Descriptive statistics for gender, skill level, and mental toughness.

\begin{tabular}{|c|c|c|c|c|c|c|c|c|c|}
\hline Gender & $\mathrm{N}$ & Skill level & Challenge & Commitment & Control emotions & Control life & Confidenceability & Confidence interpersonal & Total mental toughness \\
\hline Male & 21 & Beginner & $3.66(0.52)$ & $3.49(0.58)$ & $3.19(0.57)$ & $3.65(0.54)$ & $3.63(0.52)$ & $3.67(0.81)$ & $3.55(.44)$ \\
\hline Female & 10 & - & $3.65(0.41)$ & $3.53(0.49)$ & $3.29(0.48)$ & $3.31(0.49)$ & $3.49(0.57)$ & $3.28(0.72)$ & $3.47(.40)$ \\
\hline Male & 195 & Club/university & $3.75(0.44)$ & $3.74(0.50)$ & $3.27(0.52)$ & $3.65(0.48)$ & $3.60(0.49)$ & $3.61(0.68)$ & $3.64(.35)$ \\
\hline Female & 93 & - & $3.64(0.49)$ & $3.72(0.49)$ & $3.09(0.58)$ & $3.58(0.53)$ & $3.45(0.47)$ & $3.63(0.74)$ & $3.56(.34)$ \\
\hline Male & 138 & County & $3.85(0.41)$ & $3.86(0.43)$ & $3.25(0.47)$ & $3.82(0.45)$ & $3.69(0.49)$ & $3.85(0.63)$ & $3.75(.36)$ \\
\hline Female & 60 & - & $3.71(0.36)$ & $3.61(0.42)$ & $3.19(0.60)$ & $3.45(0.46)$ & $3.42(0.46)$ & $3.63(0.60)$ & $3.54(.33)$ \\
\hline Male & 62 & National & $3.85(0.44)$ & $3.70(0.53)$ & $3.25(0.41)$ & $3.61(0.54)$ & $3.64(0.47)$ & $3.85(0.62)$ & $3.68(.37)$ \\
\hline Female & 37 & - & $3.66(0.39)$ & $3.55(0.47)$ & $3.13(0.45)$ & $3.50(0.55)$ & $3.45(0.59)$ & $3.51(0.44)$ & $3.50(.35)$ \\
\hline Male & 38 & International & $3.81(0.38)$ & $3.66(0.53)$ & $3.25(0.48)$ & $3.56(0.55)$ & $3.63(0.49)$ & $3.54(0.64)$ & $3.61(.37)$ \\
\hline Female & 22 & - & $3.76(0.46)$ & $3.76(0.65)$ & $3.30(0.63)$ & $3.60(0.60)$ & $3.52(0.76)$ & $3.70(0.74)$ & $3.64(.52)$ \\
\hline Male & 454 & All & $3.79(0.43)$ & $3.75(0.50)$ & $3.25(0.49)$ & $3.69(0.50)$ & $3.64(0.49)$ & $3.71(0.67)$ & $3.67(.37)$ \\
\hline Female & 223 & - & $3.67(0.42)$ & $3.66(0.49)$ & $3.15(0.57)$ & $3.52(0.52)$ & $3.45(0.52)$ & $3.60(0.66)$ & $3.55(.36)$ \\
\hline
\end{tabular}

low. Such a finding would support the conceptualization of MT in the present study and suggest that MT behaves in similar ways as other personality traits (Horsburgh et al., 2009). The finding that years of experience influenced MT is in partial agreement with research by Connaughton et al. (2008). Age and years of experience are of course closely related variables ( $r=.75$ in this study). Therefore learning experiences and/or biological changes might be responsible for the small changes in the attributes underlying MT. Although more research is required to assess this (e.g., Crust, 2008), Horsburgh et al. (2009) have suggested that MT appears to have a strong genetic component. As a consequence, it would be easier to improve certain components of MT in interventions, than overall MT.

Our results revealed that there were no significant differences among athletes who participate in team or individual sports and athletes who participate in contact or non-contact sports. This finding would support the notion that MT is a personality trait that does not vary from situation to situation, as suggested by Bull et al. (2005).

A limitation of the present study is the potential for social desirability in the reporting of MT, which could have influenced findings. Future research could track athletes longitudinally in order to examine how MT, or how components of MT changes, both inter- and intra-individually (Nicholls et al., 2008) or assess perceptions of MT from significant others such as coach and peer player ratings in order to capture more accurate representations of an individual's MT. In addition, this study cannot explain how the underlying attributes of MT affect performance. In summary, MT is related to a number of different variables, but further research is required to explore the underlying mechanisms.

\section{References}

Bull, S. J., Shambrook, C. J., James, W., \& Brooks, J. E. (2005). Towards an understanding of mental toughness in elite English cricketers. Journal of Applied Sport Psychology, 17, 209-227.

Clough, P., Earle, K., \& Sewell, D. (2002). Mental toughness: The concept and its measurement. In I. Cockerill (Ed.), Solutions in sport psychology (pp. 32-45). London: Thomson.

Connaughton, D., Wadey, R., Hanton, S., \& Jones, G. (2008). The development and maintenance of mental toughness: Perceptions of elite performers. Journal of Sports Sciences, 26, 83-95.

Crust, L. (2008). A review and conceptual re-examination of mental toughness: Implications for future researchers. Personality and Individual Differences, 45, 576-583.

Golby, J., \& Sheard, M. (2004). Mental toughness and hardiness at different levels of rugby league. Personality and Individual Differences, 37, 933-942.

Horsburgh, V. A., Schermer, J. A., Veselka, L., \& Vernon, P. A. (2009). A behavioural genetic study of mental toughness and personality. Personality and Individual Differences, 46, 100-105.

Loehr, J. E. (1986). Mental toughness training for sports: Achieving athletic excellence. Lexington, MA: Stephen Greene Press.

Nicholls, A. R., Polman, R. C. J., Levy, A., \& Backhouse, S. H. (2008). Mental toughness, optimism, and coping among athletes. Personality and Individual Differences, 44, 1182-1192.

Shin, D. S., \& Lee, K. H. (1994). A comparative study of mental toughness between elite and non-elite female athletes. Korean Journal of Sport Science, 6, 85-102.

Vealey, R. S. (1988). Sport-confidence and competitive orientation: An addendum on scoring procedures and gender differences. Journal of Sport and Exercise Psychology, 10, 471-478.

Weiss, M. R. (2004). Developmental sport and exercise psychology: A lifespan perspective. Morgantown, WV: Fitness Information Technology. 